\title{
The role of nature in Tash Aw's the harmony silk factory
}

\begin{abstract}
In a world that has become increasingly industrialized and materialistic, one crucial question that has emerged is how literary works evoke a sense of eco-critical concerns regarding nature. In some literary works, nature serves merely as the setting. In some works, nature serves more than the needs of a colourful setting. It becomes an active character and an active participant in its own representation. It is accorded varied roles, as my paper will demonstrate. This paper looks at Tash Aw's The Harmony Silk Factory, which is set in colonial Malaysia in the 1930s and '40s, and divided into three parts; each part is narrated by a narrator who is also an important character in the novel. Jasper, Snow and Peter each gives their personal account of who is Johnny Lim, Jasper's father, known as a successful merchant, petty crook and great inventor. As is the case for novels set in postcolonial societies such as India, Singapore and Africa, one could easily mistake Aw, who was brought up in Malaysia but now resides in England, as another postcolonial writer, writing against the West. Initially, that was what Aw set out to do. The reader discovers soon enough that the writer not only infuses nature-based symbols and imagery but also highlights the interconnectedness between humanity and nature. Ultimately, this paper hopes to demonstrate that Aw's representations of the natural world not only add to the aesthetical value of the novel, but it also resonates with notable ecological sentiments.
\end{abstract}

Keyword: Malaysian novel in English; Nature 